\title{
All is not lost
}

\section{By resurrecting extinct infodiversity, we may save our own culture.}

\section{Scott Westerfeld}

$\mathrm{T}$ he discovery of the Landry-M'batu 'Cretan Spirals' could substantiate theories about a global proto-language from which all modern languages descend. The successful decoding of the Spirals also represents another addition to the recent spate of dramatic reconstructions of palaeodata. Whether or not the implications for panhuman language hold up, the Spirals certainly provide cheer for the generally pessimistic new science of global infometrics.

The Spirals are found on a class of Cretan pottery from about 3,800 years before the present (around the sixteenth century BCE). These 'running spirals' were produced by turning the pottery on a fast wheel while sliding a metal stylus down the side, inscribing a continuous spiral groove. The pots were then glazed, which helped preserve surface features such as the running spiral. Landry and M'batu hypothesized that any words spoken by the potter during the inscription process would vibrate the stylus, and thus be recorded in microscopic undulations of the groove, and that these sounds could be recovered by molecular mapping. After comparing analyses of several pots, the researchers discovered a consistent pattern of recorded vibrations.

The apparent habit of Cretan potters was to utter a standard prayer during inscription of the spirals. The benchmark of this (yet untranslated) prayer's structure has allowed the researchers to compensate for variations in wheel speed and other factors. Ultimately, the phonemes of the prayer and other utterances were decoded, providing audible reconstructions of Cretan speech. Comparisons with reverse-engineered Sino-Tibetan and other proto-languages are claimed to have fallen in line with the predictions of panhuman proto-language proponents. However controversial these assertions, more heartening to global infometrists was the ability of Landry and M'batu to exhume shreds of an extinct spoken language, a legacy thought buried irrecoverably by time.

Much has been written about the mass extinctions at the beginning of the third millennium. Indeed, in the two-century period of the Great Die-Off, the world lost approximately $65 \%$ of its species, with tropical rainforest biomes particularly hard hit. But global infometrics posits that this biotic die-off was merely one aspect of a generalized largescale information loss that marked the end of the millennium, the so-called Infometric Bottleneck. In addition to biotic depletion, the world lost $85 \%$ of its spoken languages; saw the end of all trade systems outside the Common Currency Unit; and the consolidation of world culture to four great religions, a single legal code and a universal software platform. Despite the common complaint that the contemporary world is too complicated, it is by any infometric measure a place of arctic simplicity.

Of course, the neck of the bottle was economic globalization, which, although it created the prosperity that $95 \%$ of humanity now enjoys, also flattened differentiation via the wholesale razing of local biomes, social

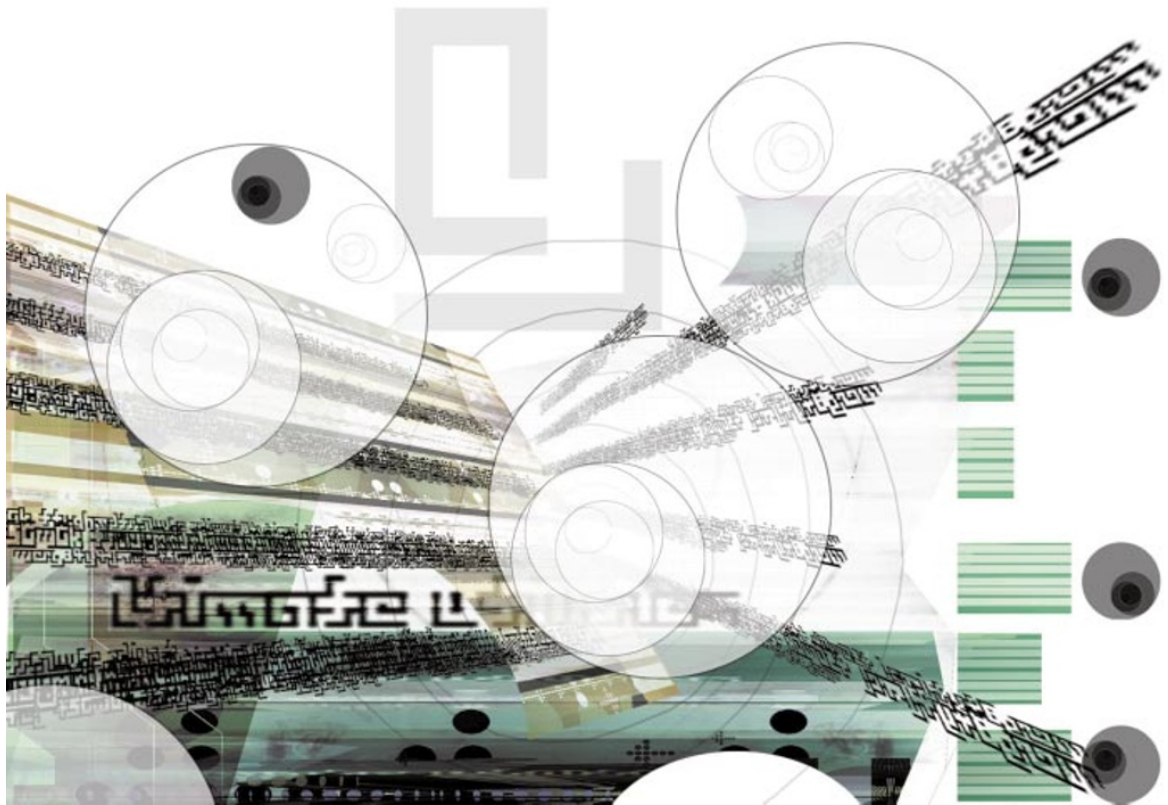

practices, and belief systems. Despite the engineering of new species, the expansion of language through emergent slang, and the cultural creolization afforded by new communications technologies, a few hundred years is simply not enough time to recreate the lost diversity that existed pre-Bottleneck.

As some recent events have shown (the currency-software crash of 2279, the Australian Biotic Collapse, the Elvis Heresy and so on), this depauperated state of the globe's information reservoirs can have perilous consequences. Simple systems are inherently less stable than diverse ones. The question is, can we reach into the past to retrieve lost information, and replenish our reserves?

New technological innovations seem to suggest that we can. The minute undulations recorded in the Landry-M'batu Spirals could not have been transcribed without molecular mapping, nor interpreted without cohomonym topology, a branch of lingui-stochastics developed only in the past few decades. The gene canon has allowed recreation of extinct species: the Siberian tiger, the blue whale, a host of red algae. Countless rainforest species are preserved in vitro and remain to be reconstructed, if the complex environmental relationships among them can be worked out. The dinosaurs have famously eluded reanimation. The lack of anything like a dinosaur womb in the present has left the codes in recovered DNA undecipherable. Apparently, some information is irrecoverably lost.

Space technologies have also recovered pre-Bottleneck information. Translight probes recently exploring the HD141569 star system recorded faint FM transmissions that left Earth in the 1980s. (Moving at a sluggish lightspeed, these transmissions are only now reaching that star.) Perhaps some decades hence, several concentric spheres of translight craft could be erected at various distances from Earth, and capture the bounty of the relativistic information wake that surrounds the planet. From these transmissions pre-Bottleneck languages, music and customs may one day be reconstructed routinely.

Much like the words recorded on the Landry-M'batu Spirals, these ancient voices would call to us faintly and in unfamiliar tongues, almost swallowed by the noise of their long journey through time. But surely we will listen carefully, their message the more precious for almost having been lost for ever.

Scott Westerfeld's latest novel is Evolution's Darling, from Four Walls Eight Windows (www.4W8W.com). 